\title{
Rehabilitation of pulmonary arteries: hybrid treatment in the unilateral absence of the pulmonary artery.
}

\author{
Jorge Cervantes-Salazar ${ }^{1}$, Jose García-Montes ${ }^{1}$, Henry Peralta-Santos ${ }^{1}$, Diego \\ Ortega-Zhindón $^{1}$, and Juan Calderón-Colmenero ${ }^{1}$ \\ ${ }^{1}$ Instituto Nacional de Cardiologia Ignacio Chavez
}

February 12, 2021

\begin{abstract}
We present two patients with history of recurrent respiratory infections, fatigue and sweating. They were diagnosed with absence of connection between the main pulmonary artery (MPA) and right pulmonary artery (RPA) and bilateral ductus arteriosus, with the RPA originating from the ductus arteriosus. Treatment was approached with a hybrid strategy: percutaneous intraluminal angioplasty with a right intraductal stent and device closure of the left ductus arteriosus and followed by surgical reconstruction with interposition of a graft from RPA to MPA. Both patients had a favorable outcome.
\end{abstract}

Rehabilitation of pulmonary arteries: hybrid treatment in the unilateral absence of the pulmonary artery.

Jorge L. Cervantes-Salazar, MD ${ }^{1}$, José A. García-Montes, MD², Henry Peralta-Santos, MD ${ }^{1}$, Diego B. Ortega-Zhindón, $\mathrm{MD}^{1}$, Juan Calderón-Colmenero, $\mathrm{MD}^{3}$

${ }^{1}$ Department of Pediatric Cardiac Surgery and Congenital Heart Disease, National Institute of Cardiology Ignacio Chávez. Mexico City, México.

${ }^{2}$ Department of Interventional Cardiology in Congenital Heart Disease, National Institute of Cardiology Ignacio Chávez. Mexico City, México.

${ }^{3}$ Department of Pediatric Cardiology, National Institute of Cardiology Ignacio Chávez, Mexico City, México.

Corresponding author: Jorge L. Cervantes-Salazar. Juan Badiano No 1. Colonia Sección XVI, Delegación Tlalpan, Mexico City, México. C.P. 14080. Phone: 5555732911. E-mail:jorgeluis.cervantes@gmail.com

Conflict of interest: None.

Funding: None.

Data availability statement: The data that support the findings of this study are available from the corresponding author, [JLCS], upon reasonable request.

Authors' contributions:

Concept/design: Cervantes-Salazar, MD; Peralta-Santos, MD; Ortega-Zhindón, MD.

Drafting article: Ortega-Zhindón, MD; Peralta-Santos, MD.

Critical revision/approval: Cervantes-Salazar, MD; García-Montes, MD; Peralta-Santos, MD; OrtegaZhindón, MD; Calderón-Colmenero, MD.

Abstract: 
We present two patients with history of recurrent respiratory infections, fatigue and sweating. They were diagnosed with absence of connection between the main pulmonary artery (MPA) and right pulmonary artery (RPA) and bilateral ductus arteriosus, with the RPA originating from the ductus arteriosus. Treatment was approached with a hybrid strategy: percutaneous intraluminal angioplasty with a right intraductal stent and device closure of the left ductus arteriosus and followed by surgical reconstruction with interposition of a graft from RPA to MPA. Both patients had a favorable outcome.

\section{Keywords:}

Absent pulmonary artery; bilateral ductus arteriosus; congenital malformation.

\section{Introduction}

Unilateral absence of a pulmonary artery is a rare congenital heart disease ${ }^{1}$ coexisting with other cardiovascular malformations, that in an isolated form are located contralateral to the aortic arch, with RPA being the most commonly affected. ${ }^{2,3}$

Patients may present with hemoptysis, recurrent respiratory infections, pulmonary hypertension or congestive heart failure, ${ }^{2}$ a comprehensive imaging evaluation, such as computed tomography, will allow to determine the therapeutic strategy, which may be a systemic-to-pulmonary shunt until direct reconstruction is advisable. ${ }^{4}$ Recent reports recommend a hybrid strategy, placing an intraductal stent and subsequential surgical reconstruction. ${ }^{5}$

We present two cases that were approved by the local institutional review board. The approval included a waiver of informed consent because it does not show personal data of patients.

\section{Description of cases}

Case 1: 4-year-old male, with a history of respiratory tract infection and heart murmur, diagnosed a year before with patent ductus arteriosus and absence of RPA (Figure 1A ). Physical examination revealed a continuous murmur in the pulmonary site. The echocardiogram showed a wide ductus arteriosus, a dilated MPA continuing with left pulmonary artery (LPA) and absence of connection with the RPA.

Cardiac catheterization showed pulmonary hypertension and double ductus arteriosus with a discontinuous pulmonary artery, where the MPA continued with the LPA while the RPA was hypoplastic with an anomalous origin in a right filiform ductus arteriosus emerging from the brachiocephalic trunk. The left ductus arteriosus was closed with a ductal occluder device and a percutaneous transluminal angioplasty with placement of a right intraductal stent was performed (Figure 1B-C ).

At one year of follow-up, normal pulmonary pressure was verified with adequate development of RPA (Figure 2A-2B ), deciding upon a surgical correction with cardiopulmonary bypass without aortic cross clamping, with surgical closure of the right ductus arteriosus and connection of RPA to MPA with a Gore-Texß 12 mm graft (Figure 2C ).

Case 2: 10-year-old female, with a history of fatigue, diaphoresis and continuous murmur in the pulmonary site. Echocardiography and computed tomography showed persistence of the ductus arteriosus and absence of RPA. Cardiac catheterization showed a double ductal system, hypoplastic RPA originating from the right ductus arteriosus emerging from the brachiocephalic trunk, a wide left ductus arteriosus and MPA continuing with LPA (Figure 3A ); additionally, an aortopulmonary collateral to the right lung and pulmonary hypertension was diagnosed. Percutaneous transluminal angioplasty was performed with placement of a right intraductal stent, transcatheter embolization of the aortopulmonary collateral with vascular plug and closure of the left ductus arteriosus with a ductal occluder device. One year later, she presented with proximal stenosis of the right ductus arteriosus for which a percutaneous transluminal balloon angioplasty was performed.

At 7 years of follow-up, she presented with normal pulmonary artery pressure and adequate development of RPA (Figure 3B ), performing a surgical repair with cardiopulmonary bypass without aortic cross clamping, 
connection of RPA to MPA with a Gore-Tex® $14 \mathrm{~mm}$ graft, in addition to the surgical closure of the right ductus arteriosus. Both patients presented a favorable postoperative outcome.

\section{Discussion}

A double ductal system is produced by the persistence of the distal segment of the sixth left and right aortic arch, ${ }^{6}$ presenting as an isolated bilateral duct or associated with congenital heart disease, such as congenital absence of one of the pulmonary arteries, among others. ${ }^{3}$

Due to its presentation at different ages and with different stages of pulmonary hypertension, it is important to determine the appropriate therapeutic approach, without a consensus on its management. Thereby, Batlivala et al. ${ }^{7}$ highlight the importance of an early diagnosis and intervention to optimize long-term results, recommending the initial diagnosis with cardiac catheterization or magnetic resonance imaging to adequately identify the anatomy and perform pulmonary unifocalization early, coinciding with Varghese et al. ${ }^{8}$ that recognition of the anatomy is essential since it proposes reconnection in patients with origin of RPA from the brachiocephalic trunk with a flap from the MPA.

Krammoh et al. ${ }^{5}$ propose a two-stage strategy, with the placement of an intraductal stent followed by direct surgical reconnection or a prosthetic graft, coinciding with the series by Mery et al, ${ }^{9}$ where they performed centralization, a surgical connection between the MPA and RPA, in a single stage in 2 patients. With the remaining 8 cases, an intraductal stent was placed in 2 of the cases and 6 were treated with a systemicto-pulmonary shunt. In a second surgical procedure 7 patients were later corrected with centralization, highlighting the rehabilitation of the pulmonary artery branches as an effective measure to restore the affected blood flow.

The critical factor that determines the treatment strategy is the size of the affected pulmonary artery, as determined by Trivedi et al. ${ }^{10}$ who found that the best strategy for patients with hypoplasia of RPA and a wide left ductus arteriosus and pulmonary hypertension, was the hybrid therapy with two stages: right intraductal stent and closure with a ductal occluder device of the left ductus arteriosus, facilitating the growth of RPA with normalization of pulmonary pressures and finally performing surgical centralization with a vascular graft with cardiopulmonary bypass similar to the proceedings in our center.

In conclusion, due to the low incidence of this defect, and its delay in diagnosis and treatment, it is important to determine the best therapeutic strategy, a situation that in our center carried the therapeutic success of the two patients presented.

\section{References}

1. Crespo D, Adrián J, Álvarez T, Zunzunegui JL. Desconexión de la arteria pulmonar derecha con doble sistema ductal. Rev Esp Cardiol. 2010; 63(2):240-252.

2. Ten Harkel AD, Blom NA, Ottenkkamp J. Isolated unilateral absence of a pulmonary artery: a case report and review of the literature. Chest. 2002; 122(4):1471-1477.

3. Freedom RM, Moes CA, Pelech A, et al. Bilateral ductus arteriosus (or remnant): an analysis of 27 patients. Am J Cardiol. 1984; 53(7):884-891.

4. Hamdan MA, Al Meshham YA, Najm HK. Successful one-stage repair of unilateral agenesis of pulmonary artery. Pediatr Cardiol. 2005; 26(5):724-726.

5. Krammoh EK, Bigras JL, Prsa M, Lapierre C, Miró J, Dahdah NS. Therapeutic strategies in children with an isolated unilaterally absent proximal pulmonary artery. Pediatr Cardiol. 2010;31(5):607-610.

6. Baspinar O, Sahin DA. Bilateral Ductal Stenting for Discontinuity of the Pulmonary Artery via the Femoral and Carotid Arteries in an Infant. Case Rep Cardiol. 2015;2015:619653.

7. Batlivala SP, McElhinney DB, Pigula FA, Marshall AC. Isolated pulmonary artery arising from a duct: A single-center review of diagnostic and therapeutic strategies. J Thorac Cardiovasc Surg. 2014; 148(5):2245-2252.

8. Varghese R, Ganesh J, Nandam J, Ravikumar S, Kothandam S. Anomalous origin of right pulmonary artery from innominate artery: Repair using pulmonary artery pedicled flap plasty. Ann Pediatr 
Cardiol. 2017; 10(3):278-280.

9. Mery CM, Molina KM, Krishnamurthy R, Fraser CD, Justino H. Pulmonary artery resuscitation for isolated ductal origin of a pulmonary artery. J Thorac Cardiovasc Surg. 2014; 148(5):2235-2244.

10. Trivedi KR, Karamlou T, Yoo SJ, Williams WG, Freedom RM, McCrindle BW. Outcomes in 45 children with ductal origin of the distal pulmonary artery. Ann Thorac Surg. 2006; 81(3):950-957.

\section{Figure Legend}

\section{Figure 1.}

A) Computerized tomography in the transversal plane, showing MPA continuing with LPA and the absence of RPA. Angiography shows: B) birth of RPA from the ductus arteriosus (arrow) and C) control after intraductal stent placement (arrow) and closure of left duct.

\section{Figure 2.}

Selective angiogram showing: A) developed RPA and B) MPA continuing with LPA. C) Intraoperative image showing the connection of RPA to MPA (arrow).

\section{Figure 3.}

Selective angiogram showing A) discontinuity of RPA and MPA continuing with LPA and B) rehabilitated $\mathrm{RPA}$ originating from the right ductus arteriosus.
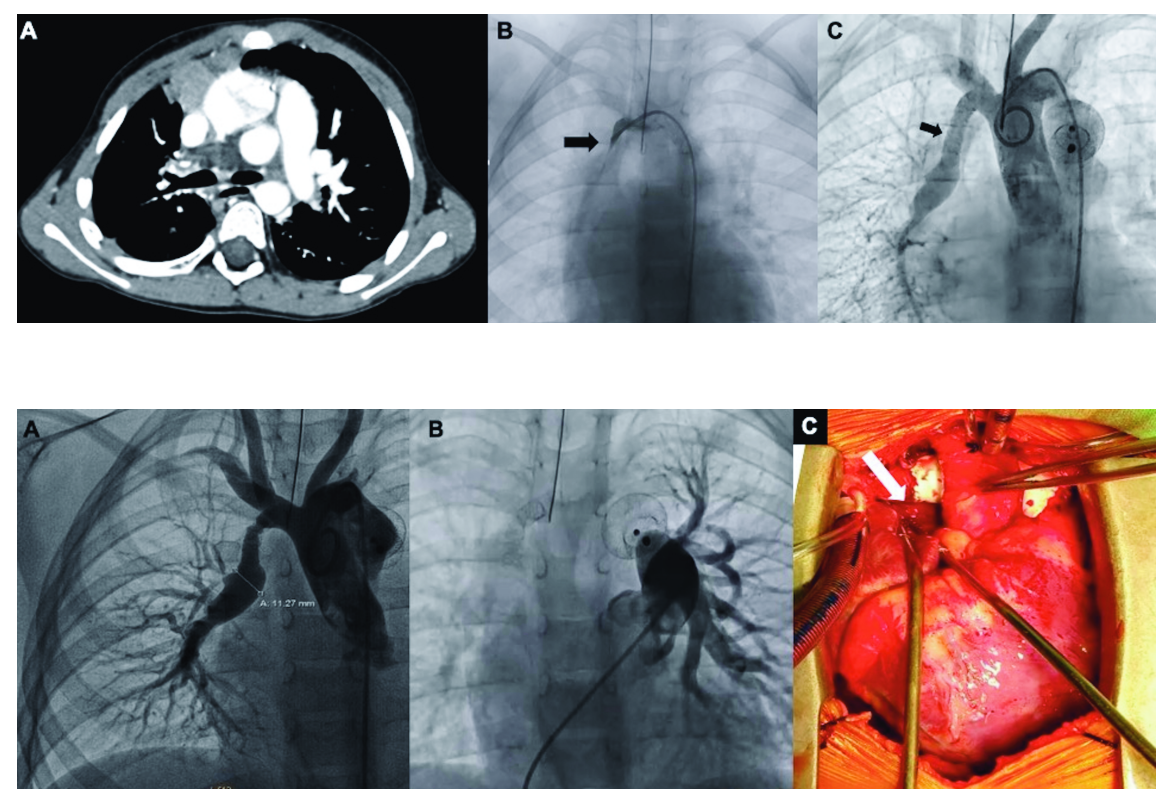


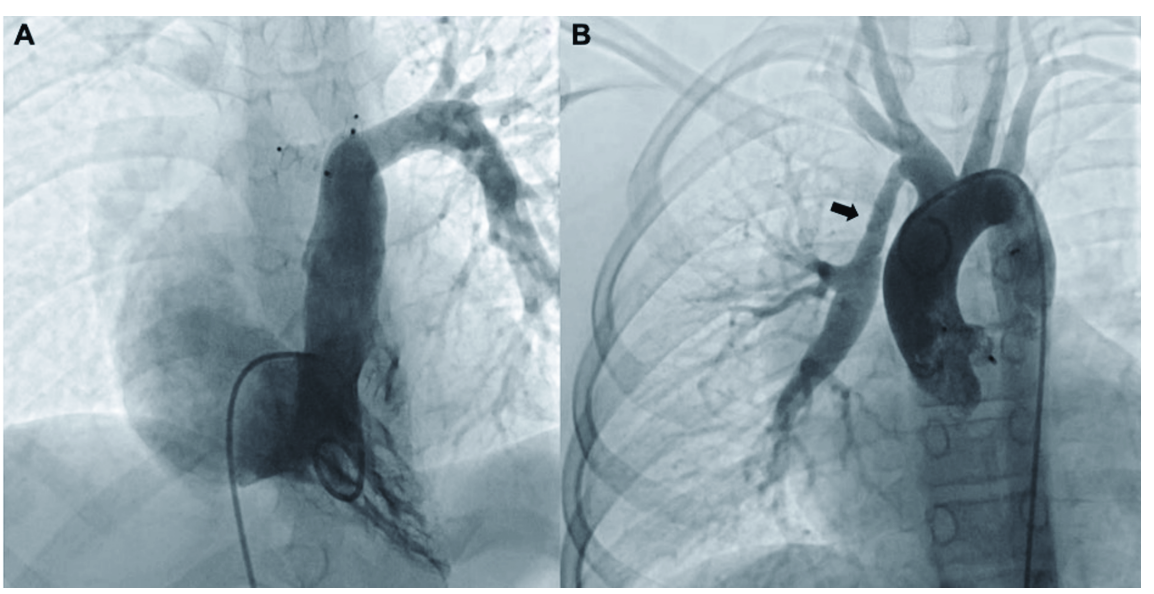

